\title{
IBS: An economic perspective on mechanisation and automation
}

\author{
Siti Syariazulfa Kamaruddin, Mohammad Fadhil Mohammad, \\ Rohana Mahbub \\ Construction Economics and Procurement Research Group, \\ Centre of Studies for Quantity Surveying, Faculty of Architecture, Planning \& Surveying, \\ Universiti Teknologi MARA (UiTM), 40450 Shah Alam, Selangor, Malaysia. \\ sitisyariazulfa@yahoo.com
}

\begin{abstract}
Incorporating mechanisation and automation in the construction process is necessary to reduce production time and costs, improve working conditions, avoiding dangerous works, allow work to be performed where people cannot do, and eventually will increase performance, and product quality. This paper discusses a preliminary study on enhancing the quality of life by adopting Industrialised Building System (IBS) focusing on the economic perspective on the use of mechanisation and automation. The sustainability principles in the IBS have always maintained the harmony between environment and construction, improve human self-respect and encourage economic development to strive for a better quality of life.
\end{abstract}

Keywords: Economic review; industrialised building system; mechanisation \& automation; sustainable construction.

eISSN 2398-4279 @ 2018. The Authors. Published for AMER ABRA cE-Bs by e-International Publishing House, Ltd., UK. This is an open access article under the CC BY-NC-ND license (http://creativecommons.org/licenses/bync-nd/4.0/). Peer-review under responsibility of AMER (Association of Malaysian Environment-Behaviour Researchers), ABRA (Association of Behavioural Researchers on Asians) and cE-Bs (Centre for EnvironmentBehaviour Studies), Faculty of Architecture, Planning \& Surveying, Universiti Teknologi MARA, Malaysia.

DOI: https://doi.org/10.21834/ajqol.v3i9.80 


\subsection{Introduction}

To fulfill the government's aspiration to transform the Malaysian construction industry to modern construction system and accomplish the implementation of the IBS Roadmap and Construction Industry Master Plan (CIMP) 2006-2015, a proper and structured planning and implementation of mechanisation and automation approach for IBS should be established. In the year 2008, a circular from the Malaysian Treasury Department, Ministry of Finance denotes the policy on full utilization of IBS to be imposed for all government projects in Malaysian. The use of IBS components for government projects must not be less than $70 \%$ (Kamar, 2009) based on a scoring system. Although the construction industry contributed only around $3 \%$ to the Gross Domestic Product in the year 2010, it makes valuable portion of the Malaysian economy. Therefore, the construction industry could be described as a substantial economic driver for Malaysian. This is in line with Brandt (2012) who stated that in the year 2011, the construction- related cluster expanded by $14.7 \%(2010: 18.9 \%)$ and was a substantial contributor to the growth of the domestic-orientated industries. The total population in Malaysian was last recorded at 28.9 million people in the year 2011 from 8.1 million in 1960, a 255 percent increase during the last 50 years (source from World Bank). It shows that, there is no short of the increasing demand and need for the construction of buildings and infrastructures. The increase in population and economic growth also demand an improvement in the quality of life (thus the purchasing power) of the population. For instance, the demand for residential buildings alone in Malaysian between the years 1995 and 2020 has projected to be around 8,850,554 units (including 4,964,560 units of new housing units) in the light of the increase in population (Yoke et. al., 2003). AlAghbari (2004) found out that there are 709,400 units to be constructed in the period of $2005-2010$.

Therefore, the quality of buildings to be constructed and completed is the most significant factor in the delivery process of buildings for the population. By comparison, the traditional method of construction which is on site or in-situ based for fabrication, installation, and construction has founded to contribute certain negative effects on sustainable construction. However, IBS construction approach, quality assured and is environmental friendly because most vital activities or components done off-site. Construction industry has started to embrace IBS as a method of attaining better construction quality and productivity, reducing risks related to occupational safety and health, alleviating issues for skilled workers and dependency on manual foreign labour, and achieving the ultimate goal of reducing the overall cost of construction. Apart from this, it offers minimal wastage, fewer site materials, a cleaner and neater environment, controlled quality, and lower total construction costs (Pan et al. 2008, Hamid et al. 2008 and Pan et al. 2007). In the end, not only that IBS is submitting to sustainable construction, it also produces quality assured products that will hopefully leads to better quality of life.

\subsection{Overview IBS in construction industry}

Industrialised Building System (IBS) as it is called is the term coined by the industry and government in Malaysian to claim the adoption of building industrialisation and the use of prefabrication of components in building construction. IBS is defined as a construction technique in which components are manufactured in a controlled environment (on or off-site), 
transported, positioned and assembled into a structure with minimal additional site work (Hamid et al., 2008; CIDB, 2007; CIDB, 2005 and CIDB, 2003). CIDB has classified the IBS systems into five categories as depicted in Table 1 (CIDB, 2003).

IBS is deemed to be characterised by it's a great degree of repetitiveness and mass production with high intensive technology. Therefore, IBS enables the optimisation of local manufacturing capabilities in order to stimulate better implementation compared to conventional construction (Rashid, 2009).

Today, the Malaysian construction industry plays an important role in generating wealth for the country in addition to the development of social, economic infrastructures, and buildings. Although the construction industry contributed only around 3\% to the Gross Domestic Product in the year 2010, it makes up an important part of the Malaysian economy due to the interaction with other industry branches such as the metals processing industry and the mechanical engineering or the tourism sector. Hence, the construction industry could be described as a substantial economic driver for Malaysian. In 2011, the constructionrelated cluster expanded by $14.7 \%$ (2010: $18.9 \%)$ and was a significant contributor to the growth of the domestic-orientated industries (Brandt, 2012).

Table 1: Categorization of IBS components in Malaysian

\begin{tabular}{|c|c|c|}
\hline IBS Introduce in & Categorization of IBS & IBS Component \\
\hline \multirow[t]{3}{*}{ Early 60's } & Badir et al. (2002) & Frame System \\
\hline & & Panel System \\
\hline & & Box System \\
\hline \multirow[t]{4}{*}{ Early 90's } & Badir and Razali (1998) & Precast concrete framing, panel and box systems \\
\hline & & Load bearing block \\
\hline & & Sandwich panel \\
\hline & & Steel frame \\
\hline \multirow[t]{5}{*}{2003} & CIDB (2003) & Pre-cast concrete framing, panel and box systems \\
\hline & & Formworks systems \\
\hline & & Steel framing systems \\
\hline & & Prefabricated timber framing systems \\
\hline & & Block work systems \\
\hline \multirow[t]{6}{*}{2010} & CIDB (2010) & Pre-cast concrete systems \\
\hline & & Formworks systems \\
\hline & & Steel framing systems \\
\hline & & Prefabricated timber framing systems \\
\hline & & Block work systems \\
\hline & & Innovative \\
\hline
\end{tabular}




\subsection{Sustainable construction through the use of mechanisation and automation: an economic appraisal}

According to Kamar et al., (2012) sustainability involves innovation and the adoption of modern method of construction through industrialisation. Modern method is where work is centrally organised, and production operations are mechanised and focused on mass production. Azman et al., (2010) reiterated that in the context of the Malaysian construction industry, it has currently been transformed into a mass production in developing the standardization of products in line with the global market. There are five degrees of industrialisation described by Richard (2005). In theory, the degree of industrialisation is shown in Figure 1. They are prefabrication, mechanisation, automation, robotic and reproduction. Prefabrication is a manufacturing process that basically takes place at a specialised facility, in which different materials are joined to form a component part of the final installation. Mechanisation comes in whenever machinery is employed to ease the workload of the labourer. Automation is a situation when the tooling (machine) totally takes over the tasks performed by the labourer. Robotics comprises the ability of the same tooling which has the multi-axis flexibility to perform diversified tasks by itself. Reproduction implies that the research and development of innovative processes is truly capable of simplifying the production process.

According to Richard (2005) the first four degrees are still more under the influence of the traditional methods of building. Prefabrication aims rather at the location on the production where the next three degrees (mechanisation, automation and robotics) aim at substituting labour with machineries (Richard, 2005). This range of this research is in between the mechanisation a bit into the earlier stage of automation implementation on site. Mechanisation can be described as the process of applying the use of mechanical plants in carrying out a task (Idoro, 2008). According to Richard (2005) the term mechanisation comes in whenever machinery is the employee to ease the work on the labour (power tools, etc.). Usually, prefabrication will be accompanied by some mechanisation (Richard, 2005).

Mahbub (2012) highlighted that the problems associated with the construction industry such as, decreasing quality and productivity, labour shortages, occupational safety and inferior working condition have highlighted the need for an innovative solution within the industry, including the push for further use of industrialization and construction automation and robotics application on site.

Andritsos (2000) described that automation is basically accepted as the technology concerned about the application of complex mechanical, electronic or completed based systems for the operation and control of production or manufacturing. Mechanisation, automation, and robotics have been proof of improving the construction process in all aspects. The most popular advantages of the mechanisation and automation in building as mentioned in various literature are: mechanising, robotising and automating construction processes can speed up construction as reducing production time also reduces the overall cost (Idoro, 2011; Gassel, 2008; Idrus, 2008; Wakisaka et al., 2000; Martinez et al., 2008; Crowley, 1998). Other than that mechanisation and automation can improve working 
conditions, avoid dangerous work, allow work to be performed that people cannot do (Gassel, 2008).

Therefore, the IBS construction approach has in many aspects proven to become more sustainable in terms of cost, time and quality through the use of prefabrication. However, the value creation of industrialisation can only be enhanced using appropriate mechanisation, automation or robotic manufacturing processes which are different from the current conventional project. Adopting mechanisation and automation will reduce the construction activities on site to just a simple transport and assembly processes and thus, becomes less complex.

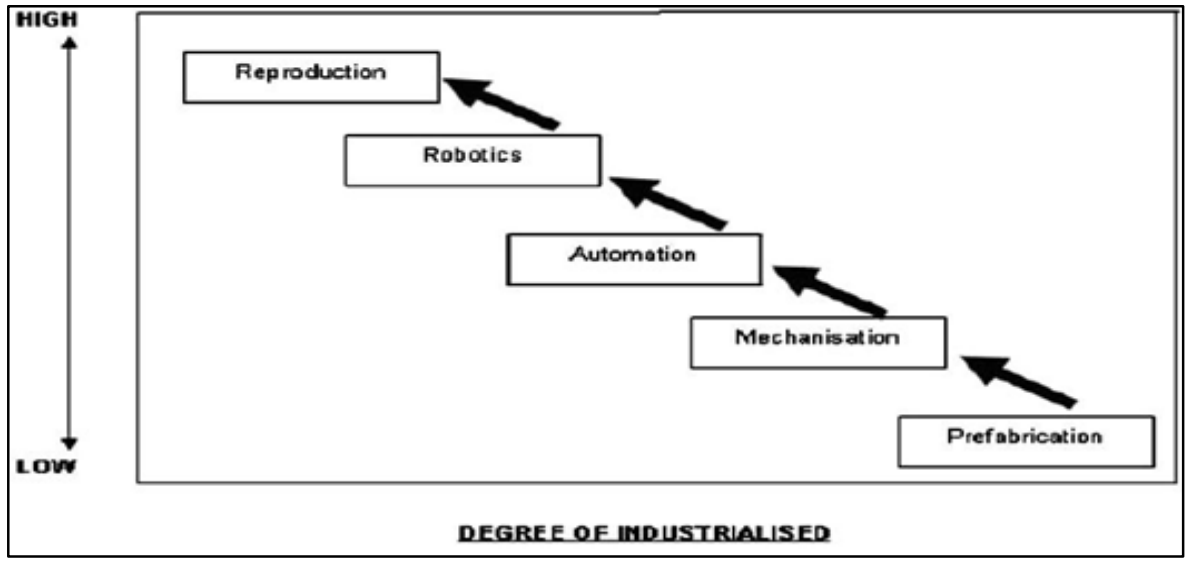

Fig.1. Degree of industrialisation

Source: Richard (2005)

\subsection{Economic review}

Studies on the economic benefit of IBS are not well documented in Malaysian (Peng et. al., 2003). This has led to a "chicken or egg" situation among construction industry professionals and builders. Many of them believe that building using IBS is overall cheaper compared with the cost of traditional construction. Past experiences, claimed by some quarters indicated that construction using IBS is more expensive due to the fierce competition by builders sticking to the traditional building method. This may well be not true. IBS construction approach also requires specialized equipment and machinery (Nawi et. al., 2005). In addition, a Research and Development (R\&D) centre, support services, and testing labs are also needed by an IBS company in the private sector (Nawi et. al., 2007a). All these facilities need continual funding and as such only companies, which are strong and stable financially could survive in use the IBS in the highly competitive industry locally and globally. This situation has made the IBS business riskier as it needs extra capital investment compared to the conventional labour-intensive method.

Kamar et. al., (2009) believes that it is extremely hard for new local companies to compete for opportunities with international competitors that are stronger in terms of financial 
capability, technology or specialisation. Therefore, the contractors prefer not to use IBS as they find it easier to stick to the traditional construction method (Nawi et. al., 2007a and Thanoon et. al., 2003). Adopting a new system means that there need to be a substantial and sustained budget, allocated time for training of human resources and specialized equipments and machineries. Based on previous studies (Kamar et. al., 2009; Nawi et. al., 2005), a lack of these superior equipments and machineries proves to be a difficult hurdle that hinders the work in IBS-based projects.

Mahbub (2012) had set up the barriers in implementation of automation and robotic in construction they are: high in cost, financial commitments in acquiring and maintaining the technologies. Beside the stated problem, Navon (1996) has listed down that economic analysis is one of the factors that need to be considered in teaching automation as part of the construction curriculum. Because of that, result from his survey shows that the automation system would be economical if it could replace at least one worker. From his survey, Navon stated that there are ten (10) parameters on the automation system economic analysis, there are:

- Initial investment cost

- Economic life

- Interest rate

- Repair and maintenance

- Operating Cost

- Transfer Cost

- Number of Saved Workers

- Labour Cost

- Robot Employment Time

- Tax Reduction

Historically Warszawski (1985) had come out with an economic feasibility study of robot employment in construction tasks. There are:

- Development cost: include all expenses associated with labour, materials and facilities used for researching, testing and evaluating of the various alternatives of robotics solutions.

- Investment costs: include depreciation and interest on investment. The parameters which must be known for their assessment are the cost of new equipment, its economic life, the salvage value at disposal and the interest charged on investment.

- Set up costs: include the installation of the equipment at its work place, the runningin, learning and programming expenses. 
- Maintenance costs: include the regular upkeep, the inspection and repairs of breakdown.

- Operation costs: the electricity consumed for robotic work.

In relation to that, even the cost involved as listing above are for robots, but it can be used for reference in costing factors of mechanisation and automation in construction. CIDB (2012) listed down several recommendation to encourage the use of mechanisation and automation in construction: they are expanding the construction machinery manufacturing industry, developing capacity and capability, strengthening research, development and commercialization, reduction of construction levy for the contractors, a leasing model for buying the machines, financial assistant and tax exemption from the government, and reduction on import duty and sales tax on the heavy machineries.

\section{Preliminary Study}

The goal in the preliminary study is to narrow things down a reasonable scope for the topic. In this research, the respondent and result summarized from the preliminaries study provides evidence from the experts and validity in enhancing the quality of life by adopting IBS focus on an economic perspective on mechanisation and automation. Enhancing is included much on issues on sustainability which include sustainable construction, green, environment and more importantly the value, cost and quality.

In this preliminary study, the distribution of these initial survey questions focused to the experts' panels. The reason of selecting expert's panel as the respondents during the survey is due to their experience in providing validity in enhancing the quality of life by adopting IBS focus on an economic perspective on mechanisation and automation. Their designation as the experts are also extended to practitioners players are; 1) CEO of IBS manufacturing, 2) Director of IBS manufacturing, 3) Manager CREAM, 4) Manager CIDB, 5) Engineer and lectures who specialized in IBS area.

\subsection{Methodology}

This paper is part of an on-going research on the mechanisation and automation in the IBS construction approach in Malaysian which is still at the initial stage. As such, the information presented is primarily based on the review of available relevant literature materials on the system.

The research methodologies employed were literature review and qualitative semistructured interviews. Literature review was the first phase of the research. Secondary data were derived from relevant books, journal articles, conference proceedings, and reports. The preliminaries study is meant to get a clear picture about the aims and objectives of the economic perspective on mechanisation and automation. 
The second phase involved the collection of primary data through semi-structured interviews. A semi-structured interview approach was employed due to the need for rich data for exploring viewpoints and gaining an initial understanding regarding the problems (Maxwell, 1996). This could facilitate to review the apparent in enhancing the quality of life by adopting IBS focus on an economic perspective on mechanisation and automation.

The Delphi method has been chosen to conduct the integral part of the preliminary study. The Delphi method can be defined as a beneficial multi-step structured communication process to achieve an unanimity response from a group of experts on problems related to the subject matter (Alexander \& Serfass, 1999). Supported by Harold \& Muray (1975) the Delphi method is a structured communication technique, originally developed as a systematic, interactive forecasting method which relies on a panel of experts. In the standard version, the experts answer questionnaires in two or more rounds. After each round, facilitator provides an anonymous summary of the expert's forecasts from the previous round as well as the reason they provided for the judgments. Thus, experts are encouraged to revise their earlier answers in light of the repliers of other members of their panel. It is believed that during this process, the range of the answers will decrease, and the group will converge towards the "correct" answer. Finally, the process is stopped after a pre-defined stop criterion and the mean or medium scores of the final rounds determine the results (Rowe and Wright, 1999). The typical Delphi method is explained using Figure 2.

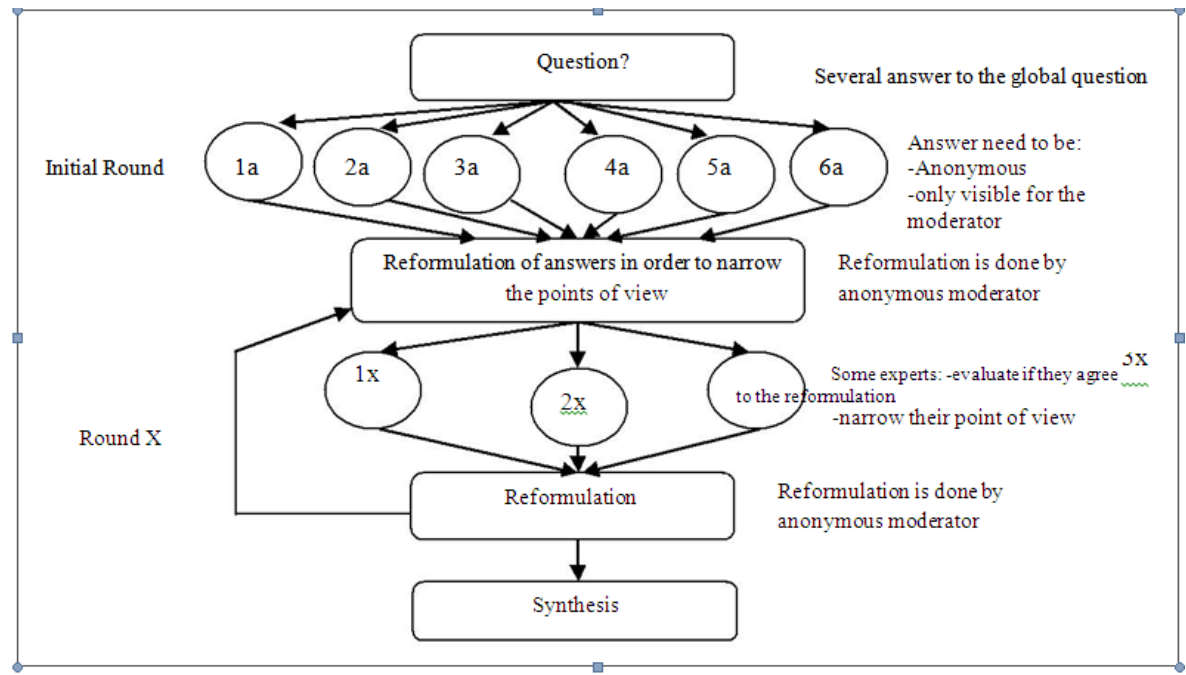

Fig. 2. The Typical Delphi method

This technique is chosen because it provides anonymity and also it helps to discover the best solution based on expressed opinions, judgements and criticism (Brown, 1968). For this preliminary study, the Delphi method will be utilised using a qualitative instrument which is the semi-structured interviews. 


\subsection{Findings and Discussions}

The analysis that is presented is the combination of literature review and results from the preliminary study in the form of exploratory interviews among a panel of experts in IBS in Malaysian. The key results from the interviews are highlighted with the apparent in enhancing the quality of life by adopting IBS focus on an economic perspective on mechanisation and automation aspect are presented below.

The exploratory interviews involved putting forward questions examining the respondents' opinion on the main problems associated with mechanisation and automation. The most popular problem chosen by the six expert panels is the high capital cost that is associated with the mechanisation and automation application. The heavily mechanized approach has also displeased a substantial number of work forces from the building construction industry. Moreover, some technologies are found to be quite complex, hi tech and expensive. This is because for them, the application of mechanisation and automation is so specialized that require high technology machines and high skilled operators which will always lead to high overall cost, whether it is produced locally or abroad.

Amongst the critical factors that will decide on the use of IBS construction approach are to resolve the foreign labour workforce issues, improvement on the quality of the project, minimize the volume of material consumed in finishing the projects, and whether it can promote a better perception towards the construction industry where they are known to be dirty, low quality and dangerous. This will also hope to be in accordance with the government policy towards meeting the national agenda or master plan. The government has also encouraged more sustainable investments in the country by providing tax incentives for such developments. Furthermore, the use of IBS components in government projects must not be less than $70 \%$ and the inclusion of IBS as part of contract documents for all new government's building. The government has also imposed a policy to limit the number of foreign workers in Malaysian in addition to other incentives and policies to promote the use of IBS in the country. The key cost drivers that will influence the cost control and management of IBS project will depends on the cost of the technology adopted. The lack of investment on heavy equipments and mechanise construction systems due to high capital investment could also hampered a move to IBS (Kamar et al., 2012). Therefore, the technological cost is the foremost concern in the global industry as the optimum or feasible development costs in using IBS will depend on the number of projects secured from public and private sector.

There can be a variety of factors that will influence the implementation of mechanisation and automation in construction with long-term sustainability. Among the factor pertinent to Malaysian would be the reduction of foreign labour, which has become a long standing national issue. According to Hamid et al., (2008), IBS adoption in Malaysian will gradually reduce the dependency on foreign labour and to save the country's loss in foreign exchange. Therefore, the effective way to reduce the number is to implement a structured and effective mechanisation and automation in the construction process of the IBS.

The glaring different between the conventional method of construction and the IBS would lie in the CAPEX (capital expenditure) and OPEX (operational expenditure). The IBS 
may look unattractive on this score, but the quality of product that it will deliver in the end will surely pay off this extra costs. Therefore, the policy to implement the IBS in the construction industry that is empowered by the government has to be taken as a long term strategy. This is to maximise the costs of mechanisation and automation system and to allow the industry to be fully ready to utilise the mechanisation and automation in construction. Another factor that is closely related to the optimum cost of IBS utilisation will be the development volume and categories of the building to be constructed must be in place before any decision can be made.

Finally the respondents unanimously agreed that the government's policy was the most critical factor that will significantly influence the choice between conventional and IBS construction approach for projects in the next 5 to 10 years. A government's policy should be imposed on the use of IBS for large developments including greater utilisation of mechanisation and automation. However, the traditional building practice must be allowed to continue for small and specialised buildings but must also be enhanced with modern and effective means of mechanisation and high skilled labour. For this type of development, replacing them with the IBS may not resulted in savings on labour cost and time of construction but it could award them with the quality and durability of the end product as well as providing a better safety and security system and more cost-effective construction methods. Basically, IBS would be feasible if there are the economics of scale. Nevertheless, the setting up of an IBS manufacturing factory requires a strong financial planning to ensure that the development can be sustained for a longer period based on the current and future demand

\subsection{Conclusion}

There is the need for the Malaysian construction industry to opt for a new and improved construction technique in order to shift from the conventional construction technique to the modern method of construction. The introduction of IBS has certainly made an impact to the industry but so far it has not achieved the level of the technology adopted by developed countries especially where mechanisation and automation are concerned. This paper presented the preliminary study of the main research to basically identify the prevailing problems and issues that are pertinent and related to the topic. It also attempts to establish the issue on sustainable construction in enhancing the quality of life by adopting IBS focusing on the economic perspective on mechanisation and automation. The results of the preliminary study are essential as a basis to develop an appraisal model on the adoption of mechanisation and automation in the IBS construction approach. Among the important interim findings for the utilisation of mechanisation and automation in IBS include the high cost of CAPEX and OPEX which will lead to a high source of financial assistance and funds, reducing the number of foreign labours, economics of scale and the government's policy. However, despite the many key issues that need to be attended the IBS end product that thrives on quality and durability must be recognised and truly appreciated. This is to address the issues on sub-standards, delays and unacceptable quality of end products normally associated with the traditional method of construction. In the end, the good quality and 
durability of buildings that are delivered to the occupiers will lead them to a better quality of living and a better quality of life. This statement is in lieu with Mahbub (2012) who highlighted that the problems associated with the construction industry such as the decreasing quality and productivity and labour shortages desperately need an innovative solution within the industry including the promotion for further use of industrialization, mechanisation and automation to be applied accordingly in the construction process.

\section{Acknowledgement}

The Author is appreciative of the expertise of the supervisory committee and to industry collaborators for their practical and applied evaluations. A remark of indebtedness is also owed to the Research Intensive Faculty (RIF) by the Universiti Teknologi MARA (UiTM), for its grant award.

\section{References}

Badir Y.F, Kadir M.R.A., \& Hashim, A.H. (2002). Industrialised building systems construction in Malaysia. Journal of Architectural Engineering, 8(1), 1923.

Bari, N.A.A., Yusuff, R., Ismail, N., \&Jaapar, A. (2011). Factors Influencing the Construction Cost of Industrialised Building System (IBS) Projects Procedia - Social and Behavioral Sciences, 35, 698-696.

CIDB.(2005). Industrialised Building Systems (IBS) Roadmap (2005).Construction Industry Development Board (CIDB) Malaysia, Kuala Lumpur.

CIDB (2010) Industrialised Building Systems (IBS) Roadmap (2011-2015). Construction Industry Development Board (CIDB) Malaysia, Kuala Lumpur.

Creswell, J. (2007). Qualitative Inquiry and Research Design: Choosing among Five Approaches. Thousand Oaks, California: Sage Publications.

Haron, N.A. Hassim, S. Kadir, M. R.A., \& Jaafar, M. S. (2005). Building Costing Comparison Between Conventional and Framework System. Journal of Technology, 43(B), UTM, Johor, Malaysia.

Haron, N. A, Rahman, H.A, Hanid, M. (2009). A Literature review of the advantages and Barriers to the implementation of Industrialised Building System (IBS) in construction Industry, Malaysia Construction Research Journal, Vol. 2 (1), pp 10-14.

Kamar et al. (2007). Industrialised Building System: Current shortcomings and the vital role of R\&D. Master Builders Association Malaysia, 2nd quarter, 62-65. Malaysia Construction Research Journal, 2(1), 20-25.

Kamar, K,A, M, Hamis, Z,A and Dzulkalnine, N (2012). Industrialised Building System (IBS) Construction: Measuring the perception of Contractors in Malaysia.

Kamar, K. A .M, Hamid, Z., Ghani, M. K., Egbu, C., And Arif, M. (2009). Towards Green And Sustainability through Industrialised Building Systems (IBS) In the Malaysian Construction Industry, Regional Conference On Environmental \& Earth Resources (Rcer 09), 7th-8th December, Pahang, Malaysia. 
Kamar, K. A. M., \& H, A, Z.,(2009). IBS: The Critical Success Factors and Way Forward. $2^{\text {nd }}$ CIDB.CREAM IBS Roundtable Workshop. Kuala Lumpur: CIDB.

Kamar, K. A. M., Alshawi, M. \& Hamid, Z. A. (2009). Barriers to Industrialised Building System (IBS): The Case of Malaysia. BuHu 9th International Postgraduate Research Conference (IPGRC) Salford, UK.

Mahbub, R. (2012). Readiness of a Developing Nation in Implementing Automation and Robotics Technologies in Construction : A Case Study of Malaysia. Civil Engineering and Architecture, USA, 6(7).

Nawi, M.N.M., Nifa, F.A.A., Abdullah, S. \& Yasin, F.M. (2007a) A Preliminary Survey of the Application of IBS in Kedah and Perlis Malaysian Construction Industry, Proceeding in Conference in Sustainable Building, Malaysia.

Nawi, M. N. M., Elias, E.M., Hamid, M. S. A. \& Yusoff, M. N. (2005) A Study of IBS Formwork Usage in the Malaysian. Construction Industry. Proceeding in National Seminar on Engineering Support Course, University Malaysia Perlis, Malaysia.

Rashid, K. A. (2009) Industrialised Building Systems: the JKR perspectives, Malaysia Construction Research Journal, 4(1), 1-9. Richard, R. B. (2005) Industrialised Building Systems: Reproduction Before Automation And Robotics, Automation-In Construction,14, 442451.

Thanoon, W. A., Peng, L. W., Kadir, M. R. A., Jaafar, M. S. And Salit, M. S. (2003) The Essential Characteristics Of Industrialised Building System In International Conference On Industrialised Building Systems Construction Industry Development Board (CIDB) Malaysia, Kuala Lumpur, Malaysia, 10-11 September 2003.

Warszawski, A. (1985). Industrialised and Automated Building Systems. Technion-Israel Institute of Technology,E and FN Spoon.

\section{Appendix A. Interview guideline}

A.1. Sustainable Construction through the Mechanisation \& Automation Approach: An Economic

What do you think would be the main problems associated with the use of mechanisation \& automation in construction?

What would be the key factors that will ultimately decide on the use of IBS construction approach in projects?

What would be the pertinent cost drivers that will influence the cost control and management of IBS projects?

What would be the critical economic and deciding factors in the implementation of mechanisation in construction that will leverage long term sustainability?

What would you think the opportunities available to conventional and IBS projects in terms of CAPEX and OPEX in relation to the used of mechanisation?

Could you RANK the five (5) critical factors that will greatly influence the choice between conventional and IBS construction approach for projects in the next 5 to 10years? 